\title{
Science teaching in university science departments
}

The "missing link" in science education?

\author{
Kostas Kampourakis ${ }^{1}$
}

Published online: 8 June 2017

(C) Springer Science+Business Media Dordrecht 2017

Science educators around the world devote their professional lives to improve the teaching and learning of science. A main part of their work is to help science teachers acquire the knowledge and skills to teach science concepts and methods in an effective manner. Achieving this is often a core goal in teacher education programmes, especially those intended for pre-service teachers. There are several important ideas underlying this goal, including among others the following:

- Teachers should teach science concepts and methods taking into account students' preconceptions, and refrain from simply transmitting scientific knowledge to them. This requires a lot on behalf of teachers: master the relevant science content knowledge and pedagogical content knowledge; select teaching approaches aiming at conceptual change; learn to choose and use appropriate questionnaires before and after their courses in order to assess their students' understanding; and more.

- Teachers should also teach aspects of nature of science in order to address their students' preconceptions and misunderstandings of how science is done, and provide them with a more authentic view of this. Research supports the conclusion that this has to be done in an explicit and reflective manner in order to be effective. Students should not just be told that science is done in this and that way, but they need to develop a thorough understanding of this.

However, many science educators working with teachers often find that all the above is difficult to achieve. Teachers intuitively find the transmission of information as the appropriate way to teach, without considering their students' preconceptions. They also do not think about explicitly and reflectively teaching about nature of science, and often they have relevant misunderstandings about it themselves. This is why science educators have to invest a lot of time and effort to improve the situation. The question is: why this is this the case?

My experience suggests a simple cause, which is not the only one but which is definitely at the heart of the problem: the way science is taught in science departments. Or, in other words,

Kostas Kampourakis

Kostas.Kampourakis@unige.ch

1 University of Geneva, Pavillon Mail, 40 Boulevard du Pont-d'Arve, 1211 Geneva 4, Switzerland 
how science teachers themselves were taught science in their undergraduate studies. Did teachers experience university courses that addressed their preconceptions? Or did they mostly experience ex cathedra teaching that provided them with tons of factual knowledge? Did anyone during their undergraduate studies talk to them about the nature of science? Or was a good portion of their practical work a process similar to implementing a cook-book recipe? With this I do not mean that nobody in university science departments teaches as they should. Indeed, especially in the USA and Canada there is a lot of attention to these matters. But the problem is that this is not the standard practice yet.

Therefore, several science teachers may come to training programs with the preconception "if I know the subject well, I can also teach it". They may also be unable to describe the general properties of a scientific model, even though they have learned numerous models in detail during their undergraduate studies. I recently finished teaching a course to science teachers with topics such as nature of science, scientific explanation, argumentation and socio-scientific issues. All these topics were presented in a way that made them pedagogically appropriate. The comment they made in the end was simply that all this is very relevant and useful to their work, and that they had never heard about these topics before. They also appreciated learning about conceptual change and experimentation in classrooms, cognitive load, motivation and a lot more that my colleague Andréas Müller and others in out Institute of Teacher Training taught. This is also the case, of course, in numerous teacher training institutes and programmes around the world.

But my question is: couldn't science teachers have been taught in a different way during their undergraduate studies? Shouldn't they have seen that their university professors cared about their preconceptions, cognitive load and motivation? Is it acceptable to have people with a degree in science who were never asked to reflect upon what scientific models are and which are their features? Who were never asked to consider the structure of causal explanations in detail? Who were never asked to think about the implications of the science they are taught for society? It seems to me that the university science departments can improve their teaching and plant the seeds for the future teachers, thus facilitating the work of science educators.

One might consider that this is not necessary because in the end most science undergraduates will not become science teachers. Therefore, the argument goes, there is no need for science departments to do all that, and this is why teacher training programmes exist anyway. I respectfully disagree. Any science undergraduate, no matter what kind of work she/he will end up doing, will most likely need to be able to communicate science to the public and to nonscientist collaborators. Therefore, any person with a science degree should be competent to diagnose the preconceptions of non-scientists and explain to them the relevant science content and how science is done. I suggest that teaching skills, and a good understanding of metascientific topics, are useful to any person with a science degree - no matter where they will end up working and insofar as this work is related to science.

So what can we do? From my own experience, nothing can change until teaching becomes as important as scientific publications for promotion and for the careers of science faculty members. Insofar as publications in prestigious journals matter most for promotion and funding, scientists working in science departments will not be motivated at all to take time from research activities and devote it to improve their teaching. But if universities emphasize the importance of what is their primary mission, that is teaching and learning, by valuing it as much as research, a lot more scientists would be motivated to think about their teaching. Indeed, many of them would actually be delighted to do so.

At the same time, science educators could have an important contribution to make. Experience has shown that changes in the way universities teach science depend on faculty 
members with science education specialties (see for instance the book by Carl Wieman, "Improving How Universities Teach Science: Lessons from the Science Education Initiative", published by Harvard University Press). Science educators live in both worlds, those of science and education, and can thus help university professors reflect upon and eventually improve their teaching. But universities have to prepare the conditions for this, starting from hiring science educators as faculty members and support them in their own research in teaching and learning at the university level. Of course, explicitly valuing teaching - at least as much as research publications - is equally important.

\section{Compliance with Ethical Standards}

Conflict of Interest The author declares no conflict of interest. 